Drke has noted that Group 3 serums are sometimes deficient in agglutinins, whereas others are of high titre. Professor Freuchen of Copenhagen informs me that, in a series of 400 transfusions, he has met the same phenomenon on fomr oceasions, and the solution of the difficulty is the invariable marlieting of high titre Group 3 stock serumsan observation reconmended to commercial firms for attention.

Mcanwhile, we have the cross-test. Dyke quotes the techmique of the American Society of Immunologists, which considers that thirty minutes at room temperature is sufficient prevention of untoward results; the present case affords evidence that this time may be insufficient. My own rule is nou to incubate the bloods at $37 \circ \mathrm{C}$. for one to one and a quarter hours in a damp chamber; the hollow-ground slide is placed in a Petri dish lined with damp filter-paper. To save time, if all is well at the end of twenty minutes the donor is bled, and when seventy-five minutes has elapsed from the time of mixing the bloods, and not before, unless the case is so desperate that the extra risk must be taken, the actual transfusion is commenced. Hitherto all trouble has been obviated, and this I. believe to be the only safe method of procedure until such time as reliable high titre Groul 3 serums are marketed.

\section{Animal Experiments.}

The value of animal experiments in elucidating the causation and indicating the necessary preventive measures in respect of this tragic condition will be apparent. Yorke found that in order to produce precipitation of injected hatemoglobin in the kidneys a dry diet (in rabbits) was essential: if they were fed on a wet diet of greens it did not occur. Blaker and Dodds' found that rabbits would pass an acid urine if fed on greens. In one case with an acid urine partial renal blockage occurred with a blood urea of $78 \mathrm{mg}$. per cent. The rabbit on wet diet had a blood nrea of $35 \mathrm{mg}$. per cent., and passed a red urine without blockage. The factors in precipitation were found to be: (1) An acid reaction ( $p H$ 5-6) which converted the pigment oxyhaemoglobin into methaemuglobin, and then probably into acid hacmatin. (2) Sodium chloride, provided it was in a concentration of not less than 1 per cent.

In paroxysmal haemoglobinuria and blackwater fever there is a similar mechanism with similar pigment casts, but the amount of haemoglobin liberated is smaller, and in these, as in the lesser degrees of transfusion haemoglobinuria, the kidney is geirerally able to weather the storm.

\section{Therapentics.}

Blaker and Dodds recomimend, on theoretical grounds, the exhibition of alkaline diuretics and transfusions of sodium carbonate. It is obvious that what must not occur is an acid, concentrated urine. In my case we tried alkaline diuretics, but, it is probable, not intensively enough. It is sufficient to say that if the urine can be kept alkaline for a few days, experiment has shown that all will be well and no renal blockage can occur.

Finally, the transfusionist must have ample warning, so as to allow the maximum amount of time necessary for cross-agglutination.

Whereas no originality is claimed for anything in this paper, except perhaps the histo-pathology of the liver in this instance, its excuse is to draw attention to the uniformity of the lesions found after death, to the valuable experimental work of Yorke, Blaker, and Dodds, and to show the necessity for a prolonged cross-agglutination test whenever practicable, and so to indicate certain means by which the tragedy of delayed incompatibility may be averted. In conclusion, I desire to thank $m \dot{y}$ colleague Mr. Arthur H. Crook for permission to publish this case.

\section{REFERENCES}

1 Blaker and Dodds: Brit. Journ. Exper. Path., vol. 6, 1925, p. 247 et seq. 2 Keynes, Geoffrey: Blood Transfusion, Oxford Medical Publica. tions, 1922. ${ }^{3}$ Bernheim, B. M. : Blood Transfusion, Haemorrhage, and the Anaemias, Lippincott Company, 1917. "Dyke, S. C. : Lancet, 1927, ii, p. $910 .{ }^{5}$ Yorke and Nauss : Annals of Trop. Med. and Parasitol., 5., 287, 1911. 0

\section{VACCINES IN THE TREATMENT OF GONORRHOEA.}

BY

\section{E. D'ARCY MCCREA, M.D., M.Ch.}

At the venereal diseases clinic of Salford Royal Hospital it was customary during the rears preceding 1924 to treat every case of gonorrhoea by a course of detoxicated gonococcal vaccine in addition to the ordinary routine treatment; however, since December, 1923, the vaccine has been discontinued. The vaccine treatment appeared to have a certain definite influence in the prevention and cure of the various complications and in shortening the period of treatment. We have therefore thought it of interest to make a comparicon-so far as it is possible-between the results obtained during the years 18\&2-23 on the one hand and those of 1924-25 on the other.

Routine Treatment.

The clinic permits of the attendance of patients thrice weekly, and the treatment (vaccine excepted) has remained unchanged from 1922 to 1925 inclusive. A urethral smear from each new patient is examined for gonococci, and if urethritis is present the patient is put on a mixture containing 10 grains of potassium citrate, 5 minims of tincture of belladonna, and $1 / 2 \mathrm{oz}$. of infusion of buchu, to be taken thrice daily, is supplied with an easily sterilized outfit containing a srringe, and with potassium permanganate lotion 1 in 8,000 , and is given a sheet on which are printed all the necessary instructions; after a short period the lotion is strengthened to 1 in 6,000, and later-somo four to six wceks after the initiation of treatment-a two-glass test demonstrates the presence or absence of a posterior urethritis. Posterior urethritis is treated by deep irrigation twice weekly with potassium permanganate lotion 1 in 6,000 , after the method of Janet, and by prostatic massage once weekly; the irrigation is varicd by employing zinc permanganate 1 in 6,000 , or silver nitrate 1 in 10,000, and sometimes mercury oxycyanide 1 in 2,000 . The progress of the patient is estimated by the two-glass test and by search for the gonococcus, both in films and by means of cultires.

\section{Standard of cure.}

Cure is not accepted inless satisfactory tests are obtained during a period of six months after treatment has been discontinued, and before the final test a return to alcohol is pexmitted. It is very neeessary to define the standard of cure; each doctor has his own criterion, and in the past the cessation of the urethral discharge was often accepted as proof of cure. It is preferable to err on the side of strictness and so avoid the possibility of those lamentable happenings which otherwise sometimes occur.

\section{The Turo-glass Test.}

The two-glass test is carried out as follows: the patient holds water for three hours prior to examination; he then passes the first specimen, and after prostatic massage the : second; both urines are at once centrifuged and examined microscopically, the average number of pus cells in a field being reported. From this count we determine the presence or absence of posterior urethritis; six to seven pus cells to a field, in the second urine, is the figure which we find from experience to indicate approximately the dividing line between a posterior urethritis and one limited to the anterior urethra-that is to say, a figure above this number denotes an extension of infection to the posterior urethra. For a cure the number in the second glass should not be above three, in a few patients four or five, the ideal being nil in both specimens.

T'accine Treatment.

The vaccine treatment, which was added to the routine procedure during the years 1922-23, consisted of two courses of vaccine-the first of ten injections of a residual pure gonococcal vaccine at weekly intervals, and the second, if posterior urethritis developed, of ten injections of a residual mixed raccine of gonococci, streptococci, staphylococci, and 
Thacillus coli, commenced during the third or fourth month. The vaccines were prepared by Dr. C. E. Jenkins, pathologist to the hospital.

\section{Results of Treatment.}

The total number of new. patients for the years 1922-25 inclusive was 424 ; this figure includes only those in whom the gonococcus was identified, and consequently, although the total figures are considerably reduced, other forms of urethritis are confidently excluded. Of these 424 patients 150 attended for a period of one month or less and then disappeared, leaving 274 for consideration-134 of 1922-23, and 140 of 1924-25. In one-third of these patients it was not the first attack of gonorrhoea. The accompanying table illustrates and serves to compare the results of treatment; the figures are, however, probably more useful for purposes of comparison than as statistics, since a proportion of the patients did not complete their treatment. The numbers dealt with in each period remain, however, approximately equal. We believe that if home treatment by means of an outfit were replaced by hospital treatment at more frequent intervals much more satisfactory results would be obtained.

\begin{tabular}{|c|c|c|c|}
\hline & & $\begin{array}{l}1922-23 \\
\text { (Vaccine). }\end{array}$ & $\begin{array}{c}1924-25 \\
\text { (No vaccine). }\end{array}$ \\
\hline Number & of patient & 134 & $\ldots 140$ \\
\hline $\mathrm{Nu}$ & without posterior urethritis & $26=19 \%$ & ... $16=11 \frac{1}{4} \%$ \\
\hline Number & with complications... & $24=18 \%$ & ... $42=30 \%$ \\
\hline Number & $\begin{array}{llll}\text { cured } & \ldots & \ldots & \ldots\end{array}$ & $66=49 \%$ & $\ldots \quad 45=32 \%$ \\
\hline $\begin{array}{c}\text { Average } \\
\text { test }\end{array}$ & $\begin{array}{ccccc}\text { period before a negative } \\
\ldots & \ldots & \ldots & \ldots & \ldots\end{array}$ & $5 \mathrm{~m}$ & $7 \frac{1}{2} n$ \\
\hline
\end{tabular}

The figures in this table require some consideration. First, it is obvious that but few patients escape a posterior urethritis; secondly, the numbers cured are to some extent misleading, for of those who do not appear as cured the majority ceased to attend before a negative test was obtained, and many of these were about to reach this stage. The real interest lies in the comparison, and it is seen at once that the percentage of complications (arthritis, epididymo-orchitis, and rheumatism) was greater in 1924-25, the percentages of cures less, and the period of attendance before the first negative test was obtained longer than in 1922-23. It is again emphasized that save for vaccine treatment the routine was in all respects the same during these four years. Some small variations may be expected between different years, but to us it appears justifiable to attribute these marked differences to the vaccine treatment.

\section{COMPLETE INVERSION OF THE UTERUS: RECOVERY.}

BY

DANIEL M. DONOVAN, L.R.C.P. AND S.En. PHYSICIAN TO THE COUNTY OF CORK LYING-IN HOSPITAL.

The very rare occurrence of the condition present in the patient whose case is described below is sufficient warrant for placing it on record, and particularly so since the treatment adopted was followed by complete recovery. According to most authors, in only 30 per cent. of these cases is such an outcome to be expected.

A married woman, aged 37, was admitted to the Ernville Lying-in Hospital, Cork, at 8 p.m. on September 17th, 1927, in labour; she complained of great pain on micturition, and the urine was found to contain blocd. She was apparently a strong healthy woman, was the mother of ten living children, and had had three miscarriages. Her menstrual history was normal, and she had never suffered from any serious illness. She had a bad time on the occasion of the birth of her first child, the labour extending, according to her own account, over three and a half days, The placenta was retained and had to be removed manually.

At 1 a.m. on September 18th she gave birth to a male child weighing 11 lb. Profuse bleeding occurred after the child had been born, and the patient collapsed. A hypodermic injection of 1 c.cm. of pituitrin was administered, followed by brandy. After the lapse of half, an hour expression of the placenta by the "Dublin method" was attempted, and sudden and complete inversion of the uterus took place; there had been no traction on the cord. Shortly before 2 a.m. I was summoned by telephone and found the patient very bad indeed. The pulse was imperceptible, the face was covered with a cold clammy sweat, and the respirations were faint and fast. I was informed that a peculiar placenta was half delivered, and discovered the uterus with the placenta covered by membranes completely external to the vulva, and extending down nearly to her knees. It was quite evident that no time must be lost if the patient's life was to be preserved. I hastily came to the conclusion that anaesthesia was out of the question; the time that would elapse before I could have the assistance of my colleagues would have been fatal. The have the assistance of my colleagues would have been fatal. The
serious, almost dying, condition of the patient did not warrwat my administcring an anaesthetic and performing the necessary my administcring an anaesthetic and performing the necessary
manipulations myself. By doing so I could not maintain satisfactory anaesthesia, and, moreover, it would have been impossible to keep my hands from becoming infected. In any case I did not think the patient was fit to take an anaesthetic. Having covered the lower abdomen and thighs with towels wrung out of normal salt solution I proceeded as follows. From where I could feel the edge of the placenta I tore through the membranes with my finger in the mid-line and completely swept them off the uterus all round. I then proceeded to separate the placenta and
found that it was very adherent at the margin, but that towards found that it was very adherent at the margin, but that towards
the centre it had already separated from the uterine wall to a considerable extent; the cavity thus created had filled with blood, which by now was one large clot. I washed over the surface of the uterus with hot salt solution, and seizing the organ with my two hands I endeavoured to reduce its size by squeezing the blood from it. I kept up this pressure for a few minutes, and then, removing my left hand, grasped the now much diminished uterus with my right hand, and was able to return it completely within the vagina. Gentle upward pressure then at once restored it to its normal position.

Having replaced the uterus I now turned my attention to the general condition of the patient, who was practically unconscious
and apparently dying. Another 1 c.cm. of pituitrin wa: administered hypodermicaliy. Two pints of normal salt solution containing 1 drachm of adrenaline solution was injected into the ixillae, and the patient was ordered $1 / 30$ grain of strychnine with $1 / 100$ grain of digitaline every four hours hypodermically. She was also given salt solution by the rectum every four hours. She regained consciousness at 5 a.m., and by that afternoon had apparently got over the grave shock, but she then complained apparently got over

Her temperature that afternoon was $97.6^{\circ} \mathrm{F}$, the pulse rate was 120 , and the respirations 32 . Rectal salines and hypodermics of strychnine and digitaline were discontinued. The temperature gradually rose to between $101^{\circ}$ and $102^{\circ} \mathrm{F}$., and she had a rigor on the third day. She was then given an intrauterine douche of cyllin solution, which was repeated every day for four days, and subsequently every alternate day for fourteen days. On the intervening days the vagina was douched with cyllin solution. She was also given $\frac{1}{2}$ drachm of the liquid extract of ergot twice daily during this time. The temperature gradually subsided and she was quite well and out of bed on the twenty-second dav. she was quite well and out of bed on the twenty-second day.
No further complications occurred, and she left hospital at the No further complications occu
end of four wecks quite well.

Complete inversion of the viterus is said to occur only once in 250,C00 cases, and is usually put down to the following causes: (1) traction on the cord; (2) too vigorous compression of the fundus; (3) sudden delivery, especially if the mother is standing; (4) exertion after delivery, as in coughing; (5) short cord of whatever etiology.

In this case none of these causes existed, except that pressure on the fundus was tried, as stated, to express the placenta. This, however, was performed by a highly skilled and very experienced nurse, and for that reason may be eliminated. Again, the condition is said to be more common in primiparae, and my patient had given birth to ten children.

Opinions are divided as to whether the placenta should be separated from the uterus before attempting to replace the latter. I have no doubt that if I had attempted replacement without previously removing the placenta I should have had considerable difficulty in dcing so; if I had succeeded I should then have had much more trouble in removing the very adherent placenta with the uterus in situ, and the extra time involved would probably have been fatal to the patient.

The fact of the patient not being anaesthetized has been already explained. It would no doubt have made things easier for me if the patient had been under the influence of an anaesthetic, but I am satisfied that delay was out of the question, and that speedy replacement of the uterus and treatment of the profound shock gave the patient the only chance, and that a poor one, of recovery.

I am indebted to my. colleague Dr. P. J. O'Brien, for whom I was acting on this occasion, for permission to publish this case. was acting on this occasion, for permission to publish this case. recovery of the patient, since he took over the case from me on the day after the birth, and continued in attendance on her till she left hospital. 